\title{
The Relationship between Hyperactivity and Mathematics Learning among a Child with Deep Deafness
}

\author{
Sahar Abdo Elsayed ${ }^{1^{*}}$, Samira Mohamed Rakza ${ }^{2 *}$ \\ ${ }^{7}$ Assistant Professor of Curriculum and Mathematics Methodology Faculty of Education in delam Prince Sattam bin Abdul Aziz \\ University, SAUDI ARABIA \\ ${ }^{2}$ Associate Professor of Cognitive Psychology University of Blida2, Language Laboratory - Knowledge and Interaction, ALGERIA \\ *CORRESPONDENCE: $\nabla$ dr.saharabdo00@gmail.com \\ ** CORRESPONDENCE: $\triangle$ rakzasamira@hotmail.fr
}

\begin{abstract}
The current research aims at finding the relationship between hyperactivity and math learning among a child with deep deafness. The research sample was 40 children from four levels of primary education, ranging in age from (10) to (17) years, the research tools was two tests: a test was used for the evaluation of mathematics, and Teacher's test of hyperactivity, and results found that deep deafness has led to the realization of the hypotheses established by the existence of a statistically significant inverse and intermediate correlation between hyperactivity and mathematical learning. Not also includes a relationship between each of the three symptoms of hyperactivity (Lack of attention, hyperactivity, and impulsivity) and learning mathematics despite the difference in degree of correlation that was in favor of the ADHD. Based on the results, the study recommendation that the most important of which was the need to the prospects of the Deaf group.
\end{abstract}

Keywords: hyperactivity, mathematics learning, a child with deep deafness

\section{INTRODUCTION}

The field of special education is one of the most complex and fertile areas. It deals with several stages of life, most notably the childhood stage, which is highly recommended by the countries and is part of its near and far-reaching strategies, because it is one of the most important turns in the life of the individual and society in general. Acquire specific behavioral patterns that later determine their level of compatibility with the environment, whether home, school, street or other formal or informal social institutions, and because this stage is sensitive in which there may be behavioral, linguistic or communicative disorders in general, Counting of the features that may accompany disability deafness, and the latter in turn received with great interest by researchers who have studied the various special characteristics of cognitive and educational for the deaf child. Studies have shown that the deaf child is no different from his peers in terms of IQ and some other cognitive characteristics, but on the other hand, activists in the field complain about the difficulty in communicating information to the student. The teacher in the field of special education makes a great effort to teach the deaf child all the means and techniques ... The field of deaf education is itself a unit of different dimensions. It focuses on the means of communication with the deaf and others on the system of information processing and how to handle the information to complete and without distortion, while others concerned with the collection and the quality of difficulties encountered because each article has its own specificity and the degree of use of

Article History: Received 12 July $2019 \bullet$ Revised 22 September $2019 \bullet$ Accepted 24 September 2019

(C) 2020 by the authors; licensee Modestum Ltd., UK. Open Access terms of the Creative Commons Attribution 4.0 International License (http://creativecommons.org/licenses/by/4.0/) apply. The license permits unrestricted use, distribution, and reproduction in any medium, on the condition that users give exact credit to the original author(s) and the source, provide a link to the Creative Commons license, and indicate if they made any changes. 
language in its teaching, which allows us to know the strengths and weaknesses, and to find the possible solutions, such as mathematics or sports education, as it is called in the field.

With the increasing role of civilization and the usefulness of mathematics in the fields of contemporary knowledge and advances in science and technology becomes important to prepare our children - all our children - a strong and intelligent preparation in mathematics (Ebid, 2016).

In this sense Mathematics is one of the most important materials with a cumulative structure, and learning mathematics in the 21 st century needs to be in line with the nature of the age. The learner is prepared to deal with its successive variables and successive technological developments (Elsayed, 2016, p. 2).

\section{Problematic}

The hyperactivity is a major developmental problem affecting children, the family, school and society as a whole. It is a common disorder among children, (20\%) of primary school children aged between 6 and 12 years. According to a report by the US Health Agency, the percentage of children in primary school is about $10 \%$ of the world's children, as demonstrated by the fourth Statistical Diagnostic Manual of Mental Disorders 4DSM. Its more common among boys than among girls, ranging from the rate of 4.1 to 9.1 , and the ratio of up to $40 \%$ of the pupils of basic education (Ibrahim, 2012, p. 558).

The disorder includes attention deficit, impulsivity, and hyperactivity. Each of these components is defined in the light of multiple behavioral criteria. Attention deficit arises in attention to distracted motives, ignoring the motivations involved, and inability to pay attention to behaviors that are characterized by lack of attention and the performance of the day-to-day activities, and the unobserved children often lose their possessions, are distracted, cannot follow instructions, and have difficulty organizing or performing tasks. These children are easily distracted, avoid tasks that require attention for a certain time range, and rush to speak outside the context of conversation, subject or boycott others, and behave before thinking because they find it difficult to wait or delay. This child is in the process of explaining. He asks, speaks and answers without being allowed to do so. Often his questions and answers are not related to the lesson or the question posed by the teacher. He also responds to the tests before he hears the instructions. There are many mistakes in the level of sports activities. And interferes in the game and does not wait for his role to come, and does not follow the rules governing the play (Al Desouki, 2006, p. 9)

The problem of excess movement is a multi-faceted situation, and the student suffering from it is often subjected to maltreatment of constant rigidity, or persistence or continuous punishment in its various forms because most of the teachers faced with this condition treat it as if it is an exception to common rules or weakness in Students with extra mobility may not be able to meet the requirements of academic achievement as usual, such as other students, because of the multiple difficulties involved in their behavior and their natural interaction with different examples around them, which assesses Donia is not qadha in the classroom and snaps in one place for more than two minutes (Amaireh, 2007, p.155-156).

Family members may accept these symptoms until they reach school age and then become a school phenomenon that deserves treatment. The child cannot concentrate on his or her lessons, which leads to difficulty in remembering and hoping for immediate gratification, with no control or impatience to achieve his / her wishes. The child, along with the auditory deficit, suffers from impaired attention and loss of mental energy in excessive motor activity.

In this regard, many studies are found the relationship between the two disorders. For example, Eldik (1994), which deals with the presentation of hyperactivity, showed that children with hearing disabilities suffer more from behavioral problems, particularly motor activity, and that it is more pronounced among the deaf.

The O'Bryant study (1995) which found the effectiveness of the cognitive program in reducing the impulse of deaf people who use total communication. Mann and Thompson (1987) and in a study using the teacher's and teacher's behavior observation card through exposure to interesting learning attitudes, resulted in an improvement in these students.

The study of Abdo and Halawa (2001, pp. 64-65) shows that the deaf child grows naturally unless there is a problem that prevents it. He also has natural mental abilities, but there is a problem in his audio system that prevents his experiences and concepts from developing during the development of the language, and early intervention in child education helps to acquire language and reduce loss of experience. And its design for learning has a significant role in achieving educational goals in addition to other factors related to the child 
itself, most importantly the homogeneity of the social and economic environment of students and the absence of other disabilities associated.

However, Sesalim (2001) agrees that there are external and internal influences that distract children from hyperactivity.

One of the primary gains and materials learned by a child in the early years of school is mathematics, which plays a set of integrative facts such as number theory, multiplication, division, and estimation. The constructional structure of mathematical abilities includes a number of abilities such as the ability to think logically in quantitative and spatial relationships, Numbers, letters, mathematical symbols, relationships and processes with flexibility in mental processes for sports activities, speed and freedom to reconstruct their direction, ability in mathematical memory, problem solving methods and guiding principles (Al-Bataniah et al., 2005 p. 170).

In the auditory deficit, which takes several degrees, including deep deafness and behavioral disorder of hyperactivity, and in view of what mathematics requires from physical, mental, and psychological mechanisms, can this child learn mathematics as his ordinary counterparts? In other words, what is the nature of the relationship between hyperactivity and learning mathematics in a child with deep deafness? This question is divided into a series of sub-questions.

\section{THEORETICAL BACKGROUND AND PREVIOUS STUDIES}

In the framework of this research and the subject of it range of studies within the limits of what is found to be presented as follows:

\section{Studies include the First Variable: Hyperactivity}

The aim of Al Samadoni study (1990) was to identify the difference between children with Attention Deficit Hyperactivity Disorder and those who are hyperactive and habitual in their performance of audiovisual tasks. The sample consisted of (84) male members aged between 11 and 12 years of primary fifth grade students. The researcher used the following tools: List of Ecclesiastical Observations of Children's Behavior, Converse List of Teachers to observe child behavior, and attention tasks. The results showed statistically significant differences in favor of people with Attention Deficit Hyperactivity Disorder activity.

Alshakhs study (1992) aimed at comparing the excessive activity and the adaptive behavior of deaf and regular children, and its relation with the care of these children. The study sample consisted of (150) deaf children. The researcher used the following tools: measuring the behavior of the child, measuring the selfconcept of children. The study found that deaf people have an effect on the behaviors of the sample members where the behavior decreases and their level of motor activity increases in comparison with the usual.

Weiss study (1989) aimed to identify some of the problems that suffer from hyperactivity and the extent of continuation during adolescence. The study consisted of 100 deaf children with hyperactivity. The researcher used the method of observation and follow-up. After five years of treatment, the study found that children younger than 11 to 17 years of age had improved significantly but had some problems with hyperactivity, hyperactivity and behavioral difficulties compared to their peers. About $70 \%$ of children whose ages ranged between 6 and 12 years old have behavioral difficulties continued until they reached the age of 18, most frequently: Weak school achievement, repetition, leakage and poor compatibility (Ibrahim, 2003, p. 17).

Sharqai study (2007) focus the Relationship between Attention Disorder with Hyperactivity and Cognitive Knowledge". The aim of the study was to find out the type of relationship between attention deficit disorder with hyperactivity and cognitive learning method. The sample consisted of 20 ordinary and troubled students. The researcher used the following tools: Test the mating of the familiar forms of Hamdi Ali al-Faramawi and the hyperactivity test of Muhammad Ali al-Nubi. The results showed a positive correlation between postcognitive, impulse and hyperactivity disorder, with significant differences between sexes, between the hyperactive, and the normal.

The aim of Gregg study (1995) was to know the effect of hyperactivity disorder on social compatibility, perception of school failure and identity, weakness of self-esteem and problems of growth and memory. The sample consisted of 18 children aged between 7 and 11 years. The researcher used the following tools: the interview, the observation, the battery of the academic achievement, the tests for measuring the behavior and the knowledge processes under study, and the remedial program based on retroactive feeding. The study found 
that hyperactivity disorder was reduced for the high level of social harmony among the sample members (Muhammad and Nubian, 2009, p. 67).

Azzab study (2016, p. 1) also found that the motor education program has a significant effect on the alleviation of hyperactivity of children aged 8 to 10 years. And the males also have significant differences between males and females because males are more active than females. The recommendations emphasized the importance of developing programs for kinetic education by researchers in the same field and on schools and other age levels. Teachers and teachers should use and apply kinetic education methods to calm and relieve n Framework of children with excess movement.

\section{Studies involving the Second Variable: Learning Mathematics}

Al-Sabagh study (2003) focus "The development strategies of thinking used by skilled teachers in the teaching of mathematics in the upper stage in Jordan". The aim of the study was to find out the effectiveness of some of the strategies used by teachers to develop the student's thinking in mathematics education. The sample consisted of a group of educated teachers from the seventh and ninth grades. The researcher used both observation and interview as data collection tools. The results show that some of the teacher's strategies are effective and that the student's thinking develops with the difference in degree (Abu Zayneh, 2005, p. 362337).

Wood et al. study (1984) aimed to find out how difficult it is for the deaf to learn both reading and mathematics. The sample consisted of 446 listeners and 414 deaf people, aged 15 to 16 years. The research team adopted the observation and the level of achievement. The study found that the level of achievement in mathematics is estimated at 3.12 years for the deaf compared to 5.5 for the listeners, they found that the difficulty in mathematics is less than the difficulty in reading and that $15 \%$ of the deaf have a suitable level for their age compared to mathematics, only in reading (Hage et al., 2006, p. 223-224).

Ohan et al. (2008) used the observations of teachers on child performance in academic tasks and social attitudes in making decisions about the classification of the type of disorder experienced by the child (Dispersion Disorder, Hyperactivity Disorder / Attention and hyperactivity) and appropriate therapeutic intervention, and the teacher is often responsible for the implementation and evaluation of therapeutic interventions for children with this disorder.

A study of Hassan found "The detection of account disorders and the treatment of numbers in Algerian children 6 to 11 years through the adaptation and regulation of ZAREKI-R battery) on the Algerian environment." The study aimed at adapting Zariki's battery to the environment Algeria. The sample consisted of 334 children. The researcher used the original battery Zariki. The study found that the battery is adapted to the Algerian environment (Hassan, 2011).

Through the search and analysis of the previous studies, this study subject is selected within the limits of knowledge, and observations as following:

- Most of the studies of hyperactivity, both among adults and deaf people, have been associated with this disorder, some cognitive processes, educational achievement, psychological aspect, or the effectiveness of a treatment program.

- Most of these studies dealt with the disorder in children from the level of primary education because the stage in which the diagnosis of hyperactivity disorder is usually diagnosed.

- There is a great lack of studies that dealt with the education of mathematics and the various variables related to this substance, whether deaf or other reversal of hyperactivity disorder.

The only study approaching the subject of our research is the Wood's study, which dealt with achievement in mathematics and reading among deaf people but did not link to hyperactivity.

All these observations made the researchers study more determined to continue our quest to verify the hypotheses they formulated at the beginning of our research.

\section{METHODOLOGY}

\section{Research Questions}

1. What is the relationship between attention deficit and math learning among a child with deep deafness?

2. What is the relationship between hyperactivity and math learning among a child with deep deafness?

3. What is the relationship between impulse and math learning among a child with deep deafness? 


\section{Research Hypotheses}

Main hypothesis: There is a relationship between hyperactivity and learning mathematics in a child with deep deafness.

\section{Secondary Assumptions}

1. There is a relationship between attention deficit and math learning among a child with deep deafness.

2. There is a relationship between excessive activity and math learning among the child with deep deafness.

3. There is a relationship between rushing and math learning among a child with deep deafness.

\section{Research Importance}

1. Review the curricula and methods used in the deaf child education.

2. Try to provide a theoretical and practical framework suitable for parents and clients in this category.

3. Try to draw more attention to this category and pay attention to it better.

\section{Research Objectives}

Knowledge of the nature of the relationship between hyperactivity and mathematical learning as well as the partial relationship between the three main symptoms of hyperactivity and learning mathematics in a child with deep deafness.

\section{Study Approach}

Based on the nature of the selected subject as a problem for this research and based on the available possibilities, a descriptive method is chosen in order to distinguish it from a set of characteristics: one of the forms of scientific analysis and explanation organized to describe a phenomenon or a specific problem and quantify it by collecting data and information about the phenomenon or problem, Classifying, analyzing and subjecting them to careful study (Khandakji \& Khandakji, 2012, p. 194).

In addition, it is done in two phases, mostly: the first stage of exploration and formulation, and the second stage of diagnosis and in-depth description, and the two phases are connected to one another (Bouhouche \& Al-zonaibat, 2001, p. 124).

\section{Search Group}

The choice of the research sample was intended, after examining the research community and the availability of deaf children. The total number of the sample was 40 children from four levels of primary education, ranging in age from 10 to 17 years.

Table 1. Distribution of sample members by gender

\begin{tabular}{ccc}
\hline Sex & Replicates & Ratio \\
\hline Males & 21 & $\% 52.5$ \\
\hline Females & 19 & $\% 47.5$ \\
\hline Total & 40 & $\% 100$ \\
\hline
\end{tabular}

Table 1 shows that the percentage of males reached $52.5 \%$ compared to the percentage of females who reached $45.5 \%$.

Table 2. The distribution of sample members by year of primary education

\begin{tabular}{ccc}
\hline School year & Replicates & Ratio \\
\hline Second Year & 13 & $\% 32.5$ \\
\hline Third Year & 6 & $\% 15$ \\
\hline Fourth year & 13 & $\% 32.5$ \\
\hline Fifth year & 8 & $\% 20$ \\
\hline Total & 40 & $\% 100$ \\
\hline
\end{tabular}

Table 2 shows that the percentage of students in the second and fourth years is the largest in terms of enumeration in the sample at $32.5 \%$, followed by the fifth year by $20 \%$ and the third year by $15 \%$. 


\section{Research Tools}

To collect sample data and to answer research hypotheses, the researchers use the following tools:

\section{A set of tests for the evaluation of mathematics}

The researchers coordinated with a group of teachers in both schools a set of tests according to each level and according to what the student had studied to the present time to serve as the evaluation tests for the second semester after presenting them to a group of qualified teachers who were satisfied.

\section{Teacher's Test of Hyperactivity}

The hyperactivity test in a teacher's conner questionnaire consists of three axes (Sesalem, 2001). Each axis of one of the main symptoms of hyperactivity: attention deficit, hyperactivity, and impulsivity. The first axis of attention deficit and consists of 20 items.

The second axis is for extra activity and consists of (19) items. The third axis is specific to the impulse, which consists of 16 items.

The answer is to choose a description of the occurrence of behavior, ranging from: Rarely, often, and always.

Where grades are given respectively: $0,1,2,3$ on each option.

Thus, the crude grade is limited to 0 and 165 degrees, which is the highest attainable level.

\section{Scale Sociometric Characteristics}

To verify the validity and accuracy of the over-motor measure, the researchers applied the measurement to a sample of 30 individuals and used the internal consistency method (alpha- Kronbach) in the stability estimation. As for honesty, they used the method of lateral comparison.

\section{Stability through internal consistency}

Table 3. The value of Alpha Kronbach

\begin{tabular}{ccc}
\hline Measurement & Sample size & Alpha Kronbach \\
\hline Hyperactivity & 30 & 0.96 \\
\hline
\end{tabular}

Table 3 shows that the value of Alpha Kronbach was estimated at 0.96 and is a very acceptable value. It can be said that the measure of hyperactivity is highly stable and can be used in this study.

\section{Honesty by way of peripheral comparison}

Table 4. The T test value for the difference between the upper and lower groups

\begin{tabular}{|c|c|c|c|c|c|}
\hline Groups & $\begin{array}{l}\text { Sample size } \\
\text { (N) }\end{array}$ & $\begin{array}{c}\text { Average } \\
\text { Arithmetic (t) }\end{array}$ & $\begin{array}{l}\text { Degree of freedom } \\
\text { (D.H.) }\end{array}$ & Value of (T) & $\begin{array}{c}\text { Level of } \\
\text { significance (a) }\end{array}$ \\
\hline High & 11 & 2.6364 & 20 & 9.55 & $\mathrm{D}$ at 0.01 \\
\hline
\end{tabular}

Table 4 shows that the value of $\mathrm{T}$ was statistically significant at the mean level of 0.01 . This means that there is a difference between the upper group and the lower group in their scores on the motor hyperactivity index. The measure of hyperactivity has the ability to discriminate between individuals in terms of their degrees and it can be said that the measurement is an acceptable degree of honesty and can be used in this study.

\section{Definition of Concepts \\ Hyperactivity}

Theoretical definition: it is a disturbance in the amount of movement the child produces that is not consistent with the chronological age (Yehia, 2003).

Procedural definition: The total number of grades obtained by a child with a deep deafness is the overall measure of hyperactivity, ranging from 0 to 165 degrees. 


\section{Learn mathematics}

Theoretical Definition: It is a process that aims to provide the learner with the basics of the concepts, relationships, methods, skills and methods of mathematical thinking. The teacher, in turn, helps the learner reach his goal by exposing him to learning situations that change his behavior in the desired face (Alsharef, 1996, p. 381).

Procedural definition: This is the mark that a child with deep deafness receives through the mathematics exam for his or her level of education.

\section{Deafness}

Theoretical Definition: Is a major deficiency or total loss of hearing that can be congenital or acquired as a result of injury to an area No audio device (Mouring, 2004, p. 123).

Procedural definition: Loss of auditory or sensory nerve (more than $90 \mathrm{~dB}$ ) Hereditary or acquired.

\section{RESULTS}

\section{Presentation and Analysis of General Hypothesis and Findings}

"There is a relationship between hyperactivity and math learning in a child with deep deafness."

\section{Presentation of the results related to the general hypothesis}

Table 5. The results of the general hypothesis

\begin{tabular}{cccccc}
\hline $\begin{array}{c}\text { Sample } \\
\text { size (N) }\end{array}$ & $\begin{array}{c}\text { Link Factor } \\
\text { Person (t) }\end{array}$ & $\begin{array}{c}\text { Degree of freedom } \\
\text { (D.H.) }\end{array}$ & $\begin{array}{c}\text { Level of } \\
\text { significance (a) }\end{array}$ & $\begin{array}{c}\text { Scheduled } \\
\text { value (T) }\end{array}$ & $\begin{array}{c}\text { Calculated } \\
\text { Value (T) }\end{array}$ \\
\hline 40 & -0.55 & 38 & 0.01 & 2.42 & -4.08 \\
\hline
\end{tabular}

Table 5 shows the results of the general hypothesis that "hyperactivity and learning of mathematics in a child with deep deafness is related to the relationship of hyperactivity and athletic learning, which is a statistical function at the level of significance, 0.01 , and the degree of freedom, 38, at the value of the scheduled "t", -4.08 .

\section{Analysis of general assumption results}

The results showed in Table 5 that there is an inverse and moderate relationship between hyperactivity and learning mathematics in a child with deep deafness. This results in the realization of the general hypothesis and thus proving its validity, and this indicates that the higher final value of the hyperactivity index, the greater the difficulty in learning and acquiring the mathematics of the child with the deep deafness. In contrast, the final value of the measure of hyperactivity decreased, as did the difficulty in learning mathematics and improving its acquisition, where the researchers noticed through Soli. The responses of sample members to the mathematics test have a set of parallel difficulties:

- They have difficulty mastering some of the basic concepts of basic processes: addition, subtraction, and division.

- They have difficulty with concepts related to the spatial value of the number: individual, tens, and hundreds.

- Difficulty in organizing and arranging numbers while performing calculations arithmetically.

- Difficult to recall and recall as tables beating.

By linking the results obtained with previous studies, they are consistent with the Weiss study (Maasoma, 2003). It was found that $70 \%$ of children aged between 6 and 12 years continued their behavioral difficulties until they reached the age of 18 , the most frequent of which were: weak school achievement, repetition, leakage.

Hassan (2011) found that the detection of account disorders and the treatment of numbers in Algerian children 6 to 11 years through the adaptation and regulation of ZAREKI-R battery.

Al Samadoni (1990) showed statistically significant differences in favor of people with Attention Deficit Hyperactivity Disorder activity.

While Sesalim (2001) agrees that there are external and internal influences that distract children from hyperactivity. 
Thus, the main question was answered by the research questions.

\section{Presentation and Analysis of the Results related to the First Partial Hypothesis}

"There is a relationship between attention deficit and math learning in a child with deep deafness."

\section{Presentation of the results related to the first partial hypothesis}

Table 6. The results of the first partial hypothesis

\begin{tabular}{cccccc}
\hline $\begin{array}{c}\text { Sample } \\
\text { size (N) }\end{array}$ & $\begin{array}{c}\text { Link Factor } \\
\text { Person (t) }\end{array}$ & $\begin{array}{c}\text { Degree of freedom } \\
\text { (D.H.) }\end{array}$ & $\begin{array}{c}\text { Level of } \\
\text { significance (a) }\end{array}$ & $\begin{array}{c}\text { Scheduled } \\
\text { value (T) }\end{array}$ & $\begin{array}{c}\text { Calculated } \\
\text { Value (T) }\end{array}$ \\
\hline 40 & -0.66 & 38 & 0.01 & 2.42 & $\mathbf{- 5 . 4 1}$ \\
\hline
\end{tabular}

Table 6 shows the results of the first partial hypothesis that "there is a relationship between attention deficit and learning of mathematics in a child with deep deafness, by using the Pierson correlation coefficient for this relationship, where 66.0 is statistically significant at the level of significance, 0.01 , at the value of " $\mathrm{t}$ " scheduled, 2.42 .

\section{Analysis of results related to the first partial hypothesis}

The results indicated in Table 6 that there is a moderate inverse relationship between attention deficit and learning of mathematics in a child with deep deafness. This results in achieving the first partial hypothesis and thus proving its validity, 66.0. This indicates that the higher the final value of the partial measurement of attention deficit, the greater the difficulty in learning the mathematics of the child with the deep deafness, and the less he gained it. In contrast, the final value of the partial measurement of attention deficit difficulty in learning Ria Come and improve the acquisition of it.

By linking the results obtained with previous studies, they are consistent with the Samadoni study (1990), which resulted in reducing performance of children with hyperactivity on the tests of write-off and audio numbers, and the combination and subtraction, due to the lack of attention, which makes the child unable to select the specific examples among a number of examples.

In this regard, many researchers have provided explanations on the causes of academic difficulties in hyperactive children with attention deficit; However, Sesalim (2001) agrees that there are external and internal influences that distract children from hyperactivity.

Thus, the first question was answered by the research questions.

\section{Presentation and Analysis of the Results related to the Second Partial Hypothesis}

"There is a relationship between hyperactivity and learning mathematics in a child with deep deafness."

Presentation of the results related to the second partial hypothesis

Table 7. The results of the second partial hypothesis

\begin{tabular}{cccccc}
\hline $\begin{array}{c}\text { Sample } \\
\text { size (N) }\end{array}$ & $\begin{array}{c}\text { Link Factor } \\
\text { Person (t) }\end{array}$ & $\begin{array}{c}\text { Degree of freedom } \\
\text { (D.H.) }\end{array}$ & $\begin{array}{c}\text { Level of } \\
\text { significance (a) }\end{array}$ & $\begin{array}{c}\text { Scheduled } \\
\text { value (T) }\end{array}$ & $\begin{array}{c}\text { Calculated } \\
\text { Value (T) }\end{array}$ \\
\hline 40 & -0.36 & 38 & 0.01 & 2.42 & $\mathbf{- 2 . 3 7}$ \\
\hline
\end{tabular}

Table 7 shows the results of the second partial hypothesis that "there is a relationship between the extra activity and the learning of mathematics in the child with deep deafness" by using the Pierson correlation coefficient to calculate this relationship, 36.0, which is statistically significant at the level indication, 0.01 , at the value of " $\mathrm{t}$ " scheduled, 2.42 .

\section{Analysis of results related to the second partial hypothesis}

The results showed in Table 8 that there was a weak inverse relationship between hyperactivity and learning of mathematics in a child with deep deafness. The mean value of the Pierson correlation coefficient for the sample scores on the partial measure of the activity, 36.0. This indicates that the higher the final value of the partial measure of the excess activity, the greater the difficulty in learning the child's deep deafness and the less he gained it. In contrast, the final value of the partial measure of the excess activity decreased, in learning math and improved their acquisition. 
By linking the results obtained with previous studies, they are consistent with (Ohan et al., 2008) shows an activity and an excessively compulsive movement around the child with deep deafness by observations of teachers on child performance in academic tasks and social attitudes in making decisions about the classification of the type of disorder experienced by the child (Dispersion Disorder, Hyperactivity Disorder / Attention and hyperactivity) and appropriate therapeutic intervention, and the teacher is often responsible for the implementation and evaluation of therapeutic interventions for children with this disorder.

Thus, the second question was answered by the research questions.

\section{Presentation and Analysis of the Results related to the Third Partial Hypothesis}

"There is a relationship between rushing and learning mathematics in a child with deep deafness."

Presentation of the results related to the third partial hypothesis

Table 8 . The results of the third partial hypothesis

\begin{tabular}{cccccc}
\hline $\begin{array}{c}\text { Sample } \\
\text { size (N) }\end{array}$ & $\begin{array}{c}\text { Link Factor } \\
\text { Person (t) }\end{array}$ & $\begin{array}{c}\text { Degree of freedom } \\
\text { (D.H.) }\end{array}$ & $\begin{array}{c}\text { Level of } \\
\text { significance (a) }\end{array}$ & $\begin{array}{c}\text { Scheduled } \\
\text { value (T) }\end{array}$ & $\begin{array}{c}\text { Calculated } \\
\text { Value (T) }\end{array}$ \\
\hline 40 & -0.34 & 38 & 0.01 & 2.42 & $\mathbf{- 2 . 2 2}$ \\
\hline
\end{tabular}

Table 8 shows the results of the third partial hypothesis that "there is a relationship between the impulse and the learning of mathematics in the child with deep deafness" by using the Pearson correlation coefficient to calculate this relationship, where, 34.0 are statistically significant, 0.01 , at a fixed value of 2.42.

\section{Analysis of results concerning the third partial hypothesis}

The results showed in Table 8 that there is a weak inverse relationship between the impulse, and learning mathematics in a child with a deep deafness, and this results in the achievement of the third partial hypothesis and thus prove its validity, where the value of the correlation coefficient Pierson to the grades of the sample on the partial measure of impulse -34.0. This indicates that all increased the final value of the partial measure of impulse was all the more difficult to learn mathematics in the child with deep deafness and less gain, and in contrast, the final value of the partial measure of impulse was reduced as the difficulty in learning and improving the acquisition of mathematics decreased.

By associating the results obtained with previous studies, the Ebrahim Samadoni (1990) study found that hyperactive children are impulsive in a way that makes them unable to finish their work and perform poorly.

In agreement with Hassan study (2011) found "The detection of account disorders and the treatment of numbers in Algerian children 6 to 11 years through the adaptation and regulation of ZAREKI-R battery on the Algerian environment." The study aimed at adapting Zariki's battery to the environment Algeria. The sample consisted of 334 children. The researcher used the original battery Zariki. The study found that the battery is adapted to the Algerian environment.

Thus, the third question was answered by the research questions.

\section{General Comment}

The results of the analysis and the interpretation we have found indicate that both the general hypothesis and the three sub-hypotheses have been achieved. They have agreed in the direction of the relationship while the degree of correlation has been different. The ADHD has been higher than the hypothesis that "attention and learning of mathematics in those with deep deafness "where the Pierson correlation coefficient was estimated at 66.0. The hyperactivity variable represented by the general hypothesis is that" hyperactivity and learning of mathematics in a child with deep deafness is associated", 55.0, and, thirdly, the excess activity representative of the sub-hypothesis. Second "there is a relationship between hyperactivity and learning of mathematics a child with deafness deep" correlation coefficient Pearson estimated, -36.0, and then finally comes the third variable impulsivity Representative Sub-Pearson correlation coefficient hypothesis may Lord, -34.0 .

These results are considered very acceptable. Several studies and several explanations were agreed upon by a group of researchers. Although all these studies are not devoted to the variables of mathematics learning, they dealt with scholastic achievement in general and did not allocate all of them to the deaf class, which may give the current research a deaf scientific value that is more important because it came more specialized, but within the scope of the research, dealt with only a small part of the total community of deaf people with profound disabilities. 


\section{CONCLUSION}

Mathematics is one of the basic educational materials in the educational system. It plays an important role in the learning of many materials, without understanding the various mathematical procedures. Learning it is difficult, sometimes impossible. It also has practical value in many professions. It also contributes to civic life through developing the ability to detect and innovate and create students' funding for accurate scientific research.

And all these activities we needed at the present time, especially with the human invasion of outer space and access to the depths of the earth and the discovery of the most complex constituents of the material and the development of information and communication system and the satellite system and so on technological and industrial development in spite of the importance of these activities.

In this study, the researchers found only few studies that have the same variable, especially in the deaf category. Most of the studies were focused on achievement in general. In contrast to the variable of hyperactivity of the variables, the current research on the hyperactivity relationship in mathematics learning in a child with deep deafness has led to the realization of the hypotheses established by the existence of a statistically significant inverse and intermediate correlation between hyperactivity and mathematical learning, also includes a relationship between each of the three symptoms of hyperactivity Lock of attention, hyperactivity, impulsivity, and learning mathematics despite the difference in degree of correlation that was in favor of the ADHD. This is the most visible representation in this category and to a medium degree, both the hyperactivity and the impulse in the order and to the weak degree, Sample and conditions of the application.

\section{RECOMMENDATIONS}

Through the field study and in light of what was reached and were noticed in the field, a number of suggestions and recommendations were suggested:

- Highlight the deaf class through the media and various seminars and lectures.

- Interest in this category throughout the year and not only in national and international events.

- Identify the different needs of this category and the category of hyperbolic by conducting studies and statistics.

- Pay attention to the preparation of educational programs for the deaf community and programming them according to a schedule that suits the deaf community needs.

- Providing adequate physical and human resources for better education for deaf children.

- Develop intensive and appropriate counseling programs for deaf and hyperactive groups and their parents to enhance their social interaction and to ensure their psychological problems.

- Integration of deaf people with moderate and disabilities directly into regular schools.

- Organizing students in deaf schools according to degree of disability.

- Opening of new centers to approximate distances and give all the opportunity to education and construction.

- Provide jobs that suit the needs of this category.

- Encourage researchers to study the various variables related to this category.

- Studying the educational methods of the deaf and its relation to the educational achievement.

- Studying the internal rules of the deaf schools and its relation to the educational achievement.

- Studying of mathematics learning and its relation to various cognitive processes.

- Studying of mathematics learning and its relationship to various psychological processes.

- Acquire ins spatial and temporal concepts and their relationship to deaf child learning.

- The impact of psychological sponsorship on learning deaf children.

- The effect of the pedagogic guarantee on learning deaf children.

- Conducting studies on the methods of education adopted by deaf children's teachers and their effectiveness.

- Hyperactivity relationship by learning the temporal and spatial concepts of the deaf child.

- The effect of hyperactivity and its relation to the social harmony of the deaf child.

- The effect of hyperactivity on the compatibility of school deaf child.

- Conducting a comparative study between the deaf and the ordinary in the same subject.

- Conducting a similar study comparing males and females. 
- Conducting another similar study comparing educational levels.

- Conducting similar studies that are more specialized to take the mathematics variable instead of one mathematical concept.

Many of the prospects remain open to the deaf group, waiting only for those who highlight it.

\section{ACKNOWLEDGEMENT}

Thanks for Deanship of Scientific Research at Prince Sattam Bin Abdulaziz University.

\section{Disclosure statement}

No potential conflict of interest was reported by the authors.

\section{Notes on contributors}

Sahar Abdo Elsayed - Assistant Professor of Curriculum and Mathematics Methodology Faculty of Education in delam Prince Sattam bin Abdul Aziz University, SAUDI ARABIA.

Samira Mohamed Rakza - Associate Professor of Cognitive Psychology University of Blida2, Algeria.

\section{REFERENCES}

Abdo, B. A.-D. K., \& Halawa, M. E.-S. (2001). Care for the handicapped both visually and physically. Egypt Alexandria.

Abu Zina, F. K. (2005). Qualitative Research Methods (i.1). Jordan: Dar Al-Mesira.

AlSamadouni, E. I. (1990). Audiovisual Attention in Children with Hyperactivity, Faculty of Education, Tanta University. 3rd International Conference on Childhood, Second Volume, 3-10 March.

Alshakhs, A. A. (1992). A Study of Adaptive Behavior and Excessive Activity in a Sample of Children with Hearing Impairments and their Relation to the Care of These Children. Research of the Fifth Annual Conference of the Egyptian Child, Center for Childhood Studies, Ain Shams University, Vol. II, 10231046.

Alsharef, A. A. (1996). Introduction to mathematics teaching. Tripoli: The Open University, Libya.

Azzab, M. R. (2016):The Effect of the Kinetic Education Program on Reducing Hyperactivity of Children (8-10 years) According to Gender, Qadisiyah Journal of Physical Education Sciences, Iraq, Vol. (16), Issue 1, March 1, Available at: http://search.mandumah.com/Record/774774

Bouhouche, A., \& Al-zonaibat, M. M. (2001). Methods of scientific research and methods of preparation of research (I.3). Ben Aknoun: University Publications, Algeria.

Ebed, W. (2016). Mathematics education for all children (I.1). Jordan, Amman: Dar Al-Mesira.

El-Dardir, A. M. A. (2004). Contemporary Studies in Educational Psychology (I.1). Egypt, Cairo: The World of Books.

Eldik, v. Th. (1994). Behavior problems with deaf Dutch boys. American Annals of the Deaf, 139, 394-399. https://doi.org/10.1353/aad.2012.0280

Elsayed, S. A. (2016). Effectiveness of using interactive computer software in developing the mathematical Power skills of Prince Sattam University students. Journal of the Mathematics Education Association. Egypt: Faculty of Education, Banha University.

Hage, C., Charlier, B., Leybart, J. (2006). Compétences cognitives, linguistiques et sociales de l'enfant sourd. collection pratiques psychologique. France: edition MARDAGA.

Hassan, L. (2010). Detection of Calculus Disorders and Number Processing in the Algerian Child (Unpublished Doctoral Thesis). University of Algiers.

Ibrahim, M. A. (2003). Arab studies in psychology. Egypt, Cairo: Dar Gharib for Printing \& Publishing.

Ibrahim, S. A. W. Y. (2012.). Brain and Attention Disorder. Alexandria: New University House. Egypt.

Khandakji, M. A.-J., \& Khandakji, N. A.-J. (2012). Methodology of scientific research contemporary educational perspective (I.1). Jordan, Irbid: The World of Modern Books.

Mann, W. C., \& Thompson, S. A. (1987). Rhetorical Structure Theory: A Theory of Text Organization. Marina del Rey, California: Information Sciences Institute, University of Southern California. 
Mourin, Y. (2004). Le petit larousse de la médecine. France, Paris: Larousse- Bordeu.

Nubi, M. A. M. (2009). Attention disorders with hyperactivity for people with special needs (I.1). Jordan, Amman: Dar Wael Publishing and Distribution.

O'Bryant, K. M., \& Fee, V. E. (1995). Predictors of depression in children with Attention Deficit-Huperactivitv Disorder (ADHD) (Unpublished master's thesis). Mississippi State University, Mississippi State.

Ohan, J. L., Cormier, N., Hepp, S. L., Visser, T. A., \& Strain, M. C. (2008). Does knowledge about attentiondeficit/hyperactivity disorder impact teachers' reported behaviors and perceptions? School Psychology Quarterly, 23(3), 436-449. https://doi.org/10.1037/1045-3830.23.3.436

Sesalem, K. S. (2001). Attention Deficit Hyperactivity Disorders. Al Ain, United Arab Emirates: University Book House.

Sharqi, S. (2007). The relationship between Attention Deficit Disorder with Hyperactivity and Cognitive Knowledge, Rush (Master Thesis). University of El Hadj Lakhdar, Algeria.

Yahia, K. A. (2003) Behavioral and emotional disorders. Amman, Jordan: 2 Dar Al-Fikr Printing, Publishing and Distribution. 